Research Journal of Pharmacology 4 (2): 31-37, 2010

ISSN: $1815-9362$

(C) Medwell Journals, 2010

\title{
Microbiological Analyses of Drug Tablets from Selected Outlets in Umuahia, Abia State, Nigeria
}

\author{
C.N. Obi and U. Nwannunu \\ ${ }^{1}$ Department of Microbiology, College of Natural and Applied Sciences, \\ Michael Okpara University of Agriculture, Umudike, P.M.B. 7267, \\ Umuahia, Abia State, Nigeria
}

\begin{abstract}
Six different types of drug tablets dispensed from containers in selected hospitals, community pharmacies and patent medicine stores were investigated for their microbial loads. Bacteria isolated include Bacillus sp., Staphylococcus aureus, Streptococci sp. and Escherichia coli, while the fungal isolates include Microsporum, Asperigillus, Trichophyton, Epidermatophyton and Penicillum $\mathrm{sp}$. Results showed that samples collected from hospitals had the lowest microbial load compared to samples collected from community pharmacies and patent medicine stores. Drug samples from Hospital A had the highest Total Heterotrophic Bacterial Count (THBC) of $3.0 \times 10^{5} \mathrm{cfu} \mathrm{mL}^{-1}$, while Hospital B had the highest coliform count of $2.1 \times 10^{5}$ cfu $\mathrm{mL}^{-1}$. Pharmacy B had the highest THBC of $4.8 \times 10^{5} \mathrm{cfu} \mathrm{mL}^{-1}$, while Pharmacies B and C had the highest coliform count of $3.0 \times 10^{5} \mathrm{cfu} \mathrm{mL}^{-1}$, respectively. Patent Medicine Store D had the highest THBC of $5.7 \times 10^{5}$ cfu $\mathrm{mL}^{-1}$, while Patent Medicine Store B and D had the highest coliform counts of $3.0 \times 10^{5} \mathrm{cfu} \mathrm{mL}^{-1}$, respectively. The tablets analyses had high microbial loads, thus drug dispensers in hospitals, pharmacies and patent medicine stores should observe strict hygienic rules to reduce or eliminate contamination of the unsealed tablets given to the patients.
\end{abstract}

$\underline{\text { Key words: Contamination, drug tablets, hospitals, microbial loads, patent medicine stores, pharmacies }}$

\section{INTRODUCTION}

The microbial quality of pharmaceuticals is influenced by the environment and quality of the raw materials used during formulation. Some disease outbreaks have been associated with the use of heavily contaminated raw materials of natural origin (Kallings et al., 1966). The incidence of micro flora in medicines especially counting tablets generally is indicated by the nature of the ingredients (whether natural or synthetic), the quality of the vehicle and the care and attitude of the personnel involved in their handling (Parker, 2000). Most raw materials for pharmaceutical products support some forms of microbial growth depending on the nutritive properties and moisture content. Hence, dry tablets are capable of undergoing some forms of microbial spoilages or degradation. The more serious problems of microbial contamination of tablets is where there is no obvious signs of spoilage hence, it is usually advisable to have knowledge of the microbial content of all drugs and medicines whether they are required to be sterile or nonsterile (Parker, 2000). Manufacturing process for tablets reduces the viability of microbial cells significantly, hence, the microbial growth is rarely observed (Parker, 1984). Contamination of medicine involves basically initial or early pioneer invaders of biodegrading microorganisms which prepare the way for later invaders. This they do by degrading complex nutrients thereby altering the surrounding $\mathrm{pH}$ and making moremoisture available (Parker, 1984). The microbiological quality at the moment of administration of non-sterile pharmaceutical dosage forms like tablets is dependent on the bio-burden of the raw materials (Khante et al., 1979), hence, the need for observing strict contamination reduction strategies at every stage of production.

Tablets and capsules constitute a large proportion of the medicines which are dispensed in modern dispensaries, though many are now present in blister packs. Situation in most developing countries like Nigeria still presents instances where drugs are supplied in bulk packs and then prescribed amount counted for them (Akerelej and Ukoh, 2003). In tropical countries such as Nigeria, pharmaceutical preparations such as tablets are frequently stored under uncontrolled conditions where

Corresponding Author: C.N. Obi, Department of Microbiology, College of Natural and Applied Sciences, Michael Okpara University of Agriculture, Umudike, P.M.B. 7267, Umuahia, Abia State, Nigeria 
the average temperature is about $31^{\circ} \mathrm{C}$ and the average relative humidity $75 \%$ and may be dispensed in non-protective packaging or even without any packaging at all (Blair et al., 1998). Dispensing of tablets from large packs is a common practice in hospitals, pharmaceutical, clinics, patent medicine stores. Some of these packs take on average of 3-4 weeks to dispense completely depending on the demand.

In some cases in Nigeria, they would take up to 6 weeks to dispense for such packages like folic acid and vitamin B complex (Onawunmi, 1999). There is yet no report on the bio-burden of tablets in large dispensing packages or containers where there are common features in hospitals, clinics, pharmacies and patent medicine stores. This could be due to under estimation of health hazards to which patients are exposed through microbial contamination of such tablets dispensed from large packages. This research aimed at determining the microbial loads of some drug tablets collected from selected outlet point $\mathrm{s}$ in umuahia, Abia state.

\section{MATERIALS AND METHODS}

Study area and source of samples: The study points are selected hospitals, community pharmacies and patent medicine stores within the Umuahia metropolis. The protocol for the study involved structured selection of representative named tablets from these hospitals, community pharmacies and patent medicine stores.

Demographic characteristics: A total of 6 different types of counting tablets were collected from 3 selected hospitals, 3 selected pharmacies and 4 selected patent medicine stores. Five tablets each of Ascorbic acid (Vitamin C), B-complex, Folic acid, Keterax, Chloroquine and Paracetamol were randomly sampled from retail containers from three Community pharmacies in different locations in Umuahia city. Similar procedure was adopted for the same drugs from retail dispensing packs from three public hospitals and four patent medicine stores also in different locations within the Umuahia metropolis.

Sample collection: Nylon hand gloves were worn and the tablets collected from the tablet container using sterile scapel. The tablets were transferred into sterile universal bottles, labelled properly and transported in the laboratory in sterile canisters.

Preparation of drug tablets: The tablets were crushed to powder using sterile laboratory motar and pestle. Two tablets each of ascorbic acid, chloroquine, folic acid, keterax, B-complex were dispersed in $2 \mathrm{~mL}$ of distilled water while two tablets of paracetamol were dispersed in $4 \mathrm{~mL}$ of distilled water. Tablets dispersions were mixed and shaken in vortex fashion for $5 \mathrm{~min}$ to dislodge possible microbial cells. The solid particles sedimented out and the supernatants were used. Six fold serial dilution of each tablet's supernatant was prepared for microbial count.

Determination of microbiological quality of tablets: About $1 \mathrm{~mL}$ aliquot of each tablet's dispersion was spread on Nutrient, MacConkey and Sabourand Dextrose Agar (SDA) plates in duplicates plates and labeled accordingly. The bacterial plates were incubated at $37^{\circ} \mathrm{C}$ for $24-48 \mathrm{~h}$, while the fungal plates were incubated at $22^{\circ} \mathrm{C}$ for 14 days. The SDA plates were fortified with $0.005 \%$ chloramphenicol antibiotic to inhibit bacterial contaminants.

Culture identification: Following growth, the microbial colonies were observed for colonial morphology and the total plate count determined. Each bacterial isolate was sub cultured on a fresh media using the Streak techniques to obtain pure isolates. The pure isolates were Gram stained and also subjected to necessary biochemical tests for complete identification of the bacterial isolates (Ogbulie et al., 1998; Cowan and Steel, 1984; Cheesbrough, 1984). Morphological features observation, slide culture technique and slide mount in Lactophenolcotton-blue of each fungal isolate was carried out according to Barnett and Hunter (1972).

\section{RESULTS AND DISCUSSION}

The result of the microbiological examination of tablets dispensed from large containers in hospitals, community pharmacies and patent medicine stores are shown in Table 1-6. The microbial loads of the samples analyzed and their mean counts are shown in Table 1-3, while the percentage occurrence of the microbial isolates from the samples collected from all the outlets are shown in Table 4-6.

The result of the research showed that all the drug tablets analyzed had bacterial and fungal growths. The bacteria isolated include Bacillus sp., Streptococci sp., Staphylococcus aureus and Escherichia coli while the fungal isolates are Microsporum sp., Penicillum sp., Trichophyton sp., Epidermophyton sp. and Aspergillus sp. From Table 1, it was observed that Hospital A had the highest Total Heterotrophic Bacterial Count (THBC) of $3.0 \times 10^{5} \mathrm{cfu} \mathrm{mL}^{-1}$ and also the highest mean hospital count of $2.73 \times 10^{5} \mathrm{cfu} \mathrm{mL}^{-1}$. This implies the tablets 
Res. J. Pharmacol., 4 (2): 31-37, 2010

Table 1: Microbial load of drug tablets dispensed in hospitals

\begin{tabular}{lccc}
\hline & \multicolumn{3}{c}{ Microbial counts } \\
Study area & Samples & NA cfu mL & MCA cfu mL \\
\hline Hospital A & 1 & $3.0 \times 10^{5}$ & $1.7 \times 10^{5}$ \\
& 2 & $2.8 \times 10^{5}$ & $1.5 \times 10^{5}$ \\
& 3 & $2.9 \times 10^{5}$ & $1.9 \times 10^{5}$ \\
& 4 & $2.6 \times 10^{5}$ & $1.7 \times 10^{5}$ \\
& 5 & $2.7 \times 10^{5}$ & $2.0 \times 10^{5}$ \\
Mean counts & 6 & $2.4 \times 10^{5}$ & $1.6 \times 10^{5}$ \\
Hospital B & 1 & $2.73 \times 10^{5}$ & $1.73 \times 10^{5}$ \\
& 2 & $2.3 \times 10^{5}$ & $1.9 \times 10^{5}$ \\
& 3 & $2.5 \times 10^{5}$ & $1.5 \times 10^{5}$ \\
& 4 & $2.0 \times 10^{5}$ & $2.1 \times 10^{5}$ \\
& 5 & $2.0 \times 10^{5}$ & $1.6 \times 10^{5}$ \\
Mean counts & 6 & $2.1 \times 10^{5}$ & $1.8 \times 10^{5}$ \\
Hospital C & 1 & $2.16 \times 10^{5}$ & $1.6 \times 10^{5}$ \\
& 2 & $2.4 \times 10^{5}$ & $1.6 \times 10^{5}$ \\
& 3 & $2.8 \times 10^{5}$ & $1.4 \times 10^{5}$ \\
& 4 & $2.5 \times 10^{5}$ & $1.9 \times 10^{5}$ \\
& 5 & $2.9 \times 10^{5}$ & $1.6 \times 10^{5}$ \\
& & $1.6 \times 10^{5}$ & $1.7 \times 10^{5}$ \\
Mean counts & & $1.8 \times 10^{5}$ & $1.8 \times 10^{5}$ \\
& & $2.33 \times 10^{5}$ & $1.66 \times 10^{5}$ \\
\hline
\end{tabular}

NA-Nutrient Agar, MCA-McConkey Agar

Table 2: Microbial loads of drug tablets dispensed in community pharmacies

\begin{tabular}{lccc}
\hline & \multicolumn{3}{c}{ Microbial count } \\
\cline { 2 - 4 } Study area & Samples & N/A cfu mL & MCA cfumL \\
\hline Pharmacy A & 1 & $4.0 \times 10^{5}$ & $2.5 \times 10^{5}$ \\
& 2 & $4.5 \times 10^{5}$ & $2.3 \times 10^{5}$ \\
& 3 & $3.9 \times 10^{5}$ & $2.7 \times 10^{5}$ \\
& 4 & $4.2 \times 10^{5}$ & $2.5 \times 10^{5}$ \\
Mean counts & 5 & $4.0 \times 10^{5}$ & $2.1 \times 10^{5}$ \\
Pharmacy B & 6 & $4.1 \times 10^{5}$ & $1.9 \times 10^{5}$ \\
& 1 & $4.12 \times 10^{5}$ & $2.33 \times 10^{5}$ \\
& 2 & $4.8 \times 10^{5}$ & $3.0 \times 10^{5}$ \\
& 3 & $4.4 \times 10^{5}$ & $2.9 \times 10^{5}$ \\
& 4 & $3.8 \times 10^{5}$ & $2.5 \times 10^{5}$ \\
Mean counts & 5 & $4.2 \times 10^{5}$ & $2.9 \times 10^{5}$ \\
Pharmacy C & 6 & $3.9 \times 10^{5}$ & $2.2 \times 10^{5}$ \\
& 1 & $2.6 \times 10^{5}$ & $2.3 \times 10^{5}$ \\
& 2 & $3.95 \times 10^{5}$ & $2.63 \times 10^{5}$ \\
& 3 & $4.7 \times 10^{5}$ & $2.8 \times 10^{5}$ \\
& 4 & $4.5 \times 10^{5}$ & $2.6 \times 10^{5}$ \\
& 5 & $4.3 \times 10^{5}$ & $3.0 \times 10^{5}$ \\
& 6 & $4.0 \times 10^{5}$ & $2.3 \times 10^{5}$ \\
Mean counts & & $4.1 \times 10^{5}$ & $2.5 \times 10^{5}$ \\
\hline
\end{tabular}

NA-Nutrient Agar, MCA-McConkey Agar

collected from this hospital are dispensed to the patients at under hygienic condition-a factor that made it possible for the drugs to be contaminated to the degree recorded from the research. The same hospital had the second highest mean coliform count of $1.73 \times 10^{5} \mathrm{cfu} \mathrm{mL}^{-1}$. From Hospital A too, the 4 bacterial and 5 fungal genera isolated from the tablets were found among all the samples collected from the hospital. This is also a sign of low hygienic standards both during drug storage and dispensing by the hospital staff.

From Table 2, Pharmacy B had the highest THBC of $4.8 \times 10^{5} \mathrm{cfu} \mathrm{mL}^{-1}$ as well as the highest coliform count of $3.0 \times 10^{5} \mathrm{cfu} \mathrm{mL}^{-1}$. This result is of great concern because
Table 3: Microbial loads of drug tablets dispensed in patent medicine stores

\begin{tabular}{lccc}
\hline & & Microbial count & \\
& & - & \\
Study area & Samples & N/A cfu mL & MCA cfu mL \\
\hline Patent medicine store A & 1 & $4.9 \times 10^{5}$ & $2.7 \times 10^{5}$ \\
& 2 & $4.5 \times 10^{5}$ & $2.4 \times 10^{5}$ \\
& 3 & $4.3 \times 10^{5}$ & $2.6 \times 10^{5}$ \\
& 4 & $4.6 \times 10^{5}$ & $2.3 \times 10^{5}$ \\
Mean counts & 5 & $4.0 \times 10^{5}$ & $2.1 \times 10^{5}$ \\
Patent medicine store B & 6 & $4.2 \times 10^{5}$ & $2.6 \times 10^{5}$ \\
& 1 & $4.42 \times 10^{5}$ & $2.45 \times 10^{5}$ \\
& 2 & $4.7 \times 10^{5}$ & $3.0 \times 10^{5}$ \\
& 3 & $4.4 \times 10^{5}$ & $2.5 \times 10^{5}$ \\
& 4 & $4.2 \times 10^{5}$ & $2.7 \times 10^{5}$ \\
Mean counts & 5 & $4.5 \times 10^{5}$ & $2.3 \times 10^{5}$ \\
Patent medicine store C & 6 & $3.9 \times 10^{5}$ & $2.7 \times 10^{5}$ \\
& 1 & $4.38 \times 10^{5}$ & $2.2 \times 10^{5}$ \\
& 2 & $4.8 \times 10^{5}$ & $2.6 \times 10^{5}$ \\
& 3 & $4.7 \times 10^{5}$ & $2.9 \times 10^{5}$ \\
& 4 & $4.4 \times 10^{5}$ & $2.5 \times 10^{5}$ \\
Mean counts & 5 & $4.2 \times 10^{5}$ & $2.3 \times 10^{5}$ \\
Patent medicine store D & 6 & $4.0 \times 10^{5}$ & $2.5 \times 10^{5}$ \\
& & $4.42 \times 10^{5}$ & $2.0 \times 10^{5}$ \\
& 2 & $5.7 \times 10^{5}$ & $2.46 \times 10^{5}$ \\
Mean count & $2.7 \times 10^{5}$ \\
& 3 & $4.6 \times 10^{5}$ & $2.5 \times 10^{5}$ \\
& 4 & $4.8 \times 10^{5}$ & $3.0 \times 10^{5}$ \\
& 5 & $4.5 \times 10^{5}$ & $2.4 \times 10^{5}$ \\
& 6 & $4.3 \times 10^{5}$ & $2.1 \times 10^{5}$ \\
& & $4.68 \times 10^{5}$ & $2.3 \times 10^{5}$ \\
& & & $2.50 \times 10^{5}$ \\
\hline
\end{tabular}

NA-Nutrient Agar, MCA-McConkey Agar

the values recorded against this pharmacy are higher than that recorded against Hospital B discussed earlier. This result is a source of worry because many private hospitals in Umuahia metropolis source their drugs from the individually owned pharmacies within the city.

Thus by implication, it means that these hospitals purchase drugs that are already contaminated. In addition, the difference in microbial loads with which the tablets from the pharmacies exceed those from the hospitals arose most probably due to poor hygienic standards associated with the staff who dispense the tablets to the customers which are the terminal users of the drugs.

Table 4 showed that Staphylococcus aureus had the highest percentage occurrence (83.3\%) among the hospitals and $100 \%$ among the pharmacies and PMS, respectively. The high percentage occurrence of Staphylococcus aureus was perhaps due to the fact that this bacterium is part of the normal flora of the skin (Onawunmi, 1999; Waterman et al., 1973) and regular contact with the tablets or the spoon used in dispensing the tablets from their containers greatly increased the rate of contact of this bacterium with the drug tablets.

Streptococcus sp. is a normal flora of the throat (Joanne et al., 2008). Hence, its association with the drug tablets (Table 4-6, respectively) could be due to talking, laughing, yawning and sneezing while attending to the 
Res. J. Pharmacol., 4 (2): 31-37, 2010

Table 4: Percentage occurrence of microbial isolates from drug tablets dispensed at hospitals

\begin{tabular}{|c|c|c|c|c|c|c|c|c|c|}
\hline Hospitals & $\begin{array}{l}\text { Staphylococcus } \\
\text { aureus }\end{array}$ & E. coli & $\begin{array}{l}\text { Bacillus } \\
\text { sp. }\end{array}$ & $\begin{array}{l}\text { Streptococcus } \\
\text { sp. }\end{array}$ & $\begin{array}{l}\text { Aspergillus } \\
\text { sp. }\end{array}$ & $\begin{array}{l}\text { Penicillium } \\
\text { sp. }\end{array}$ & $\begin{array}{l}\text { Microsporium } \\
\text { canis }\end{array}$ & $\begin{array}{l}\text { Trichophyton } \\
\text { mentagrophyte }\end{array}$ & $\begin{array}{l}\text { Epidermophyton } \\
\text { flocossum }\end{array}$ \\
\hline \multicolumn{10}{|l|}{ A } \\
\hline 1 & + & - & - & - & + & + & + & - & - \\
\hline 2 & - & + & - & + & + & - & + & + & - \\
\hline 3 & + & + & - & - & - & + & - & - & + \\
\hline 4 & + & - & + & - & + & - & + & - & + \\
\hline 5 & - & + & - & - & + & - & + & - & - \\
\hline 6 & + & - & - & - & + & - & - & + & + \\
\hline $\begin{array}{l}\text { Total } \\
\text { B }\end{array}$ & 67 & 50 & 17 & 17 & 83.3 & 17 & 50 & 33.3 & 50 \\
\hline 1 & + & + & - & + & + & - & - & - & + \\
\hline 2 & + & - & - & - & - & - & - & + & + \\
\hline 3 & + & - & - & + & + & + & - & - & - \\
\hline 4 & - & + & - & + & + & - & - & - & - \\
\hline 5 & + & - & - & + & + & - & + & - & + \\
\hline 6 & + & - & - & - & - & - & + & + & - \\
\hline $\begin{array}{l}\text { Total } \\
\text { C }\end{array}$ & 83.3 & 33.3 & 0 & 67 & 67 & 17 & 33.3 & 33.3 & 50 \\
\hline 1 & + & - & - & + & + & - & - & - & - \\
\hline 2 & + & + & - & - & + & - & - & - & - \\
\hline 3 & + & - & - & - & - & - & - & - & - \\
\hline 4 & - & - & + & - & - & - & - & - & + \\
\hline 5 & - & + & - & + & + & - & + & - & - \\
\hline 6 & + & + & - & - & - & - & - & - & - \\
\hline Total & 67 & 50 & 17 & 33.3 & 50 & 0 & 33.3 & 0 & 17 \\
\hline
\end{tabular}

Table 5: Percentage occurrence of microbial isolates from drug tablets dispensed at pharmacies

\begin{tabular}{|c|c|c|c|c|c|c|c|c|c|}
\hline Pharmacy & $\begin{array}{l}\text { Staphylococcus } \\
\text { aureus }\end{array}$ & E. coli & $\begin{array}{l}\text { Bacillus } \\
\text { sp. }\end{array}$ & $\begin{array}{l}\text { Streptococcus } \\
\text { sp. }\end{array}$ & $\begin{array}{l}\text { Aspergillus } \\
\text { sp. }\end{array}$ & $\begin{array}{l}\text { Penicillium } \\
\text { sp. }\end{array}$ & $\begin{array}{l}\text { Microsporium } \\
\text { canis }\end{array}$ & $\begin{array}{l}\text { Trichophyton } \\
\text { mentagrophyte }\end{array}$ & $\begin{array}{c}\text { Epidermophyton } \\
\text { flocossum }\end{array}$ \\
\hline \multicolumn{10}{|l|}{ A } \\
\hline 1 & + & + & - & - & + & - & + & + & - \\
\hline 2 & + & + & - & + & + & - & + & - & - \\
\hline 3 & + & - & - & + & + & - & + & - & - \\
\hline 4 & + & - & - & + & + & + & - & - & + \\
\hline 5 & + & - & + & - & - & - & - & + & - \\
\hline 6 & + & + & - & - & + & - & - & - & - \\
\hline Total & 100 & 50 & 17 & 50 & 83.3 & 17 & 33.3 & 33.3 & 17 \\
\hline \multicolumn{10}{|l|}{ B } \\
\hline 1 & + & + & + & + & + & - & - & - & + \\
\hline 2 & - & + & - & + & + & - & - & - & - \\
\hline 3 & + & + & - & - & + & - & - & - & - \\
\hline 4 & - & - & - & + & + & - & - & - & - \\
\hline 5 & + & + & + & - & + & - & - & - & - \\
\hline 6 & + & - & - & - & + & - & - & - & - \\
\hline Total & 67 & 67 & 33.3 & 50 & 100 & 0 & 0 & 0 & 17 \\
\hline \multicolumn{10}{|l|}{$\mathrm{C}$} \\
\hline 1 & + & - & - & + & + & + & - & - & - \\
\hline 2 & - & + & + & - & - & - & + & - & - \\
\hline 3 & + & + & - & - & + & - & + & - & - \\
\hline 4 & + & - & - & - & + & - & - & - & + \\
\hline 5 & - & + & - & + & + & + & - & - & + \\
\hline 6 & + & + & + & - & - & - & - & - & - \\
\hline Total & 67 & 67 & 33.3 & 33.3 & 67 & 17 & 33.3 & 0 & 33.3 \\
\hline
\end{tabular}

customers. Where these unhygienic and unethical habits are not checked, the area these drug tablets are dispensed would develop microbial flora that would continuously re-contaminate the sterile ones. Bacillus sp. is a normal flora of the soil so its presence on the drug tablets was most probably due to contamination during loading of the drug cartons, transportation, off-loading and storage in the ware houses. Accumulation of used drug cartons in the ware houses and patent medicine stores as well as dirty surroundings could also offer free traffic flow of Bacillus into the drug tablets especially as this bacterium is a spore former. Such spores could persist in the drug dispensing environment unless organized steps are taken to keep the environs tidy. Furthermore, the occurrence of $E$. coli among all the tablets Mcollected from the hospitals, pharmacies and patent medicine stores is another source of great concern with respect to hygienic practices that go on in these places. This is because 
Res. J. Pharmacol., 4 (2): 31-37, 2010

\begin{tabular}{|c|c|c|c|c|c|c|c|c|c|}
\hline $\begin{array}{l}\text { Patient Medicine } \\
\text { Store (PMS) }\end{array}$ & $\begin{array}{l}\text { Stophylococcus } \\
\text { cureus }\end{array}$ & E. coli & $\begin{array}{c}\text { Bacillus } \\
\text { sp. }\end{array}$ & $\begin{array}{l}\text { Streptococcus } \\
\text { sp. } \\
\end{array}$ & $\begin{array}{l}\text { Aspergillus } \\
\text { sp. }\end{array}$ & $\begin{array}{l}\text { Penicilliumsp } \\
\text { sp. }\end{array}$ & $\begin{array}{l}\text { Microsporium } \\
\text { canis }\end{array}$ & $\begin{array}{l}\text { Trichophyton } \\
\text { mentagrophyte }\end{array}$ & $\begin{array}{l}\text { Epidermophyton } \\
\text { flocossum }\end{array}$ \\
\hline \multicolumn{10}{|l|}{$\overline{\mathrm{PMS} A}$} \\
\hline 1 & + & + & - & + & + & - & + & - & - \\
\hline 2 & + & + & - & - & + & - & - & - & + \\
\hline 3 & + & - & + & - & + & - & - & + & - \\
\hline 4 & - & - & - & - & + & + & + & + & + \\
\hline 5 & + & - & - & + & + & - & - & - & - \\
\hline 6 & - & + & - & + & - & - & - & - & - \\
\hline $\begin{array}{l}\text { Total } \\
\text { PMS B }\end{array}$ & 67 & 50 & 17 & 50 & 83.3 & 17 & 33.3 & 33.3 & 50 \\
\hline 1 & + & - & - & + & - & - & - & + & - \\
\hline 2 & - & + & + & + & + & - & + & - & + \\
\hline 3 & + & - & + & - & + & + & + & - & - \\
\hline 4 & + & + & - & - & + & - & - & + & + \\
\hline 5 & + & + & - & + & + & - & + & - & + \\
\hline 6 & + & + & - & - & + & - & - & - & - \\
\hline \multicolumn{9}{|l|}{ PMS C } & 50 \\
\hline 1 & + & + & + & + & + & - & + & - & + \\
\hline 2 & + & - & + & + & + & + & - & + & + \\
\hline 3 & + & + & - & + & - & - & - & - & - \\
\hline 4 & - & - & - & + & + & - & - & - & + \\
\hline 5 & + & + & - & - & + & - & + & - & - \\
\hline 6 & + & - & - & - & - & - & - & + & - \\
\hline \multicolumn{9}{|l|}{ PMS D } & 50 \\
\hline 1 & + & + & + & - & + & - & + & - & - \\
\hline 2 & + & - & - & - & + & + & - & + & - \\
\hline 3 & + & + & - & - & + & + & - & - & + \\
\hline 4 & + & + & - & + & - & - & + & - & + \\
\hline 5 & + & + & - & - & + & - & - & - & - \\
\hline 6 & + & - & - & + & + & - & + & + & + \\
\hline Total & 100 & 67 & 17 & 33.3 & 83.3 & 33.3 & 50 & 33.3 & 50 \\
\hline
\end{tabular}

E. coli has the human colon as its natural habitat (Joanne et al., 2008) and its presence in water and food is a strong indication of faecal contamination. Within the hospitals, pharmacies and patent medicine stores the analyzed samples were collected; the only source of this organism remains the toilet. Therefore, the presence of this indicator of faecal contamination on the drug tablets is most probably due to recent cross-contamination of the tablets with human especially the hands after visiting the toilets. Results from Table 3 showed that Patent Medicine Store (PMS) D had the highest THBC of $5.7 \times 10^{5} \mathrm{cfu} \mathrm{mL}^{-1}$. This was the highest microbial load value recorded from this research against a source of sample collection and still a pointer to poor hygienic practices that prevail in such places. Many of the youths who learn the practice of drug dispensing at PMS know little or nothing about the relationships between personal hygiene and human health with respect to drug dispensing.

Dispensers and Nurses use a range of applicators (Spoons, plates, brushes, pads and spatulas) during medicament administration particularly in tropical countries. When reused, they easily become contaminated and may be responsible for perpetuating contamination between fresh stocks of products
(Onawunmi, 1999). Results from Table 3-5 showed that hospitals had the lowest incidence of microbial contamination than the pharmacies and PMS examined. This could be due to the less casual attention to personal hygiene on the part of dispensers in community pharmacies and patent medicine stores compared with hospitals. The expected higher turnover in microbial load and hence less exposure of an opened container could explain the lower incidence in the hospitals. Most community pharmacies and patent medicine stores have largely untrained dispensers, hence the dispensary benches, spoons, trays are untidily kept. This unhygienic attributes coupled with the high level of unhygienic disposition of the environment could explained the high incidence of microorganisms isolated from the tablets especially tablets from patent medicine stores as shown in Table 4 and 5 , respectively when compared with Table 3.

The presence of Penicillium sp. in the tablets (Tables 4-6) is a sign of spoilage. The hundreds of thousands of spores produced by this fungus are greatly encouraged by the relative humidity of the tablets which is high than it should be. Some of these tablets like folic acid contain the requisite micro elements which support the growth of the fungal isolates and with time the 
spoilage of these will become obvious to the naked eye (as physical discolourations and mouldy growths) due to the accumulation of fungal hyphae and the metabolic wastes.

At the time these organisms are isolated from the tablets, the contamination is still hidden from the naked eye. But with time with the build-up of hyphae and metabolic waste, the contamination and subsequent spoilage will become obvious that these tablets will be rejected by the customers. However, this happens rarely due to the rapid rate at which these tablets are purchased. Even at that the microbial contamination is on at microscopic level.

It is noteworthy that Penicillium sp. was not isolated from Hospital C (Table 4) and Pharmacy B (Table 5). Aspergillus is known to cause opportunistic respiratory tract infection called Aspergillosis when the spores are inhaled in sufficient dose (Joanne et al., 2008). This could lead to nosocomial infection to patients who queue up to collect their drugs in the hospitals or pharmacies and patent medicine stores and then to the personnels who are daily exposed to the spores in the dispensaries and drug stores.

Therefore, its isolation from the tablets (Table 4-6, respectively) is of major health concern. As a spore former, it is very possible for the drug dispensers and the patients to continually inhale the spores of this fungus as it continues to grow and sporulate on the tablets and drug cartons. This could result in serious health hazards following ingestion of highly contaminated tablets by patients whose immunity are already compromised by illness.

An opportunistic microorganism such as Aspergillus sp. which is generally harmless in its normal environment can become pathogenic in a compromised patient (Joanne et al., 2008). Because the incidence of this pathogen on the tablets collected from the hospitals is quite high (Table 4-6), Aspergillus-contaminated drug tablets dispensed in hospitals could be a contributor to cases of aspergillosis as part of nosocomial respiratory tract infections.

\section{CONCLUSION}

It was observed that Epidermophyton, Trichophyton and Microsporum species, all pathogens of superficial mycoses, thus their presence on the tablets indicates that some of the drugs dispensers at the hospitals, pharmacies or patent medicine store might have active cases of tinea infections from which the pathogen contaminated the tablets. The matter might be worse as these attendants do not put on any form of protective wears like hand gloves, especially as tinea infections chronic and non-threatening to life. Thus, body-to-drug contact is well established in these places.

\section{RECOMMENDATIONS}

Personnels who handle drugs especially exposed tablets must routinely put on properly laundered over-all or laboratory coats, hand gloves and nose masks to exclude excessive droplets from nasal passages and buccal cavity that are generally associated with sneezing, coughing or talking. Hand washing facilities must be available and usable.

The toilets must be cleaned regularly and adequately disinfected. Also, persons employed to clean the toilets and bathrooms should be restricted from handling drug tablets. Air conditioners should be installed in all drug dispensing stores as this will help reduce the growth of microorganism. Above all, the use more cheaply designed multi-dose packs which dispense tablets individually through a shutter release aperture without having to open the container cover would ultimately revolutionize large package dispensing drug tablets.

\section{REFERENCES}

Akerelej, J.O. and G.C. Ukoh, 2003. Aspects of microbial contamination of tablets. Trop. J. Pharm. Res., 1: 23-28.

Barnett, H.L. and B.B. Hunter, 1972. Illustrated Genera of Imperfect Fungi. 3rd Edn., Burgess Publishing Company, Minneapolis, ISBN-10: 0808702661, pp: 331.

Blair, T.C., G. Buckton and S.F. Bloomfield, 1998. Preservation of Solid Oral Dosage Forms. In: Microbial Quality Assurance in Pharmaceuticals Cosmetics and Toiletries, Bloomfieled, S.F., R. Baird, R.E. Leak and R. Leech (Eds.). Ellis Horwood Ltd., Chrischester, pp: 104-118.

Cheesbrough, M., 1984. Medical Laboratory Manual for Tropical Countries. Microbiology Butterworth and Co. Ltd., Britain, pp: 198-200.

Cowan, S.T. and K.J. Steel, 1984. Manual for Identification of Medical Bacteria. 2nd Edn., Cambridge University Press, Cambridge.

Joanne, M.W., M.S. Linda and J.W. Christopher, 2008. Prescott, Harley and Klein's Microbiology. 7th Edn., McGraw Hill, New York, pp: 1088.

Kallings, L.O., L. Silver Stople and F. Emerfeldt, 1966. Microbiological contamination of medical preparations. Act Pharma. Soc., 3: 219-228.

Khante, S., R.L. Nikpre and S.B. Joshi, 1979. Microbial contamination studies in sterile and non-sterile pharmaceutical formulations in consumers storage conditions. India J. Hospital Pharma., 1: 114-117. 
Ogbulie, J.N., J.C. Uwaezuike and S.I. Ogiehor, 1998. Introductory Microbiology Practical. 1st Edn., Springfield Publishers, London, pp: 162.

Onawunmi, G.O., 1999. Microbial contamination of oral and tropical Pharmaceuticals: Manufactured in Nigeria. West Afr. J. Pharma., 13: 58-63.

Parker, M.S., 1984. The preservation of oral dosage forms. Int. J. Pharma. Tech. Prod. Mfr. 5: 20-24.
Parker, M.S., 2000. Microbiological Contamination and preservation of Pharmaceutical Preparations In: Pharmaceutical: The science of dosage from design. Aulton, M.E. Churchill Livingstone Churchill Livingstone.

Waterman, R.F., E.D. Sumner, J.N. Baldwin and F.W. Warren, 1973. Survival of Staphylococcus aureus on pharmaceutical oral solid dosage forms. J. Pharma. Sci., 62: 1317-1320. 